\title{
O DUPLO E O INQUIETANTE NO FANTÁSTICO DE GUY DE MAUPASSANT
}

Jorge de Azevedo Moreira (CPII)

Recebido em 15 mai 2019. Jorge de Azevedo Moreira é Doutor em Língua Aprovado em 20 ago 2019. Portuguesa, pela UFRJ e Mestre em Língua Francesa e Literaturas de Língua Francesa pela UFRJ. Professor de Francês do Colégio Pedro II e Pesquisador do NEFB / CP2 - Núcleo de estudos franco-brasileiros.

Resumo: Este artigo se organiza em torno de algumas reflexões relacionadas às diferentes maneiras pelas quais o duplo, tema recorrente na literatura fantástica, figura em Guy de Maupassant. Para isso, partiremos de certos pontos teóricos ligados à antropologia (o confronto entre a mentalidade arcaica e a mentalidade positiva, tal como Jean Fabre define) e à psicanálise (a sensação de inquietante abordada por Sigmund Freud). Demonstraremos, além disso, que a própria estrutura das narrativas curtas de base realista do século XIX mantém importantes relações com o duplo, situação particularmente observável nos textos de Maupassant. É esse o ponto de vista proposto por Thierry Ozwald, segundo o qual o termo novela (nouvelle) só pode ser empregado para se referir às narrativas curtas daquele século, em razão do caráter fenomenológico destas: a novela marcaria uma crise da consciência individual, da qual o duplo é um signo. Nesse contexto, as narrativas de Maupassant nos mostram uma realidade instável, 
ameaçadora, até mesmo apavorante, com sua produção fantástica encarnando o paroxismo desse processo de crise subjetiva.

Palavras-chave: literatura fantástica; literatura francesa; Guy de Maupassant.

Résumé: Cet article s'organise autour de quelques réflexions concernant les différentes manières dont le double, thème récurrent dans les récits de la littérature fantastique, figure chez Guy de Maupassant, I'un des maîtres de ce genre. Pour ce faire, on partira de certains points théoriques liés à l'anthropologie (la confrontation) entre la mentalité archaïque et la mentalité positive, tel que la définit Jean Fabre et à la psychanalyse (la sensation de l'inquiétante étrangeté abordée par Sigmund Freud). On démontrera en plus que la structure narrative des récits courts de base réaliste du XIXe siècle garde elle-même d'importants rapports avec le double, situation particulièrement remarquable dans les textes de Maupassant. C'est le point de vue proposé par Thierry Ozwald, selon lequel le terme nouvelle ne peut être employé que pour se référer aux récits courts de ce siècle-là, en raison de leur caractère phénoménologique: la nouvelle marquerait une crise de la conscience individuelle, dont le double est un signe. Dans ce contexte, les récits de Guy de Maupassant nous montrent une réalité instable, menaçante, voire effrayante, sa production fantastique incarnant le paroxysme de ce processus de crise subjective.

Mots-clés: littérature fantastique; littérature française; Guy de Maupassant.

\section{INTRODUÇÃO}

Ao longo da tradição literária, inúmeras são as narrativas em que elementos sobrenaturais figuram: desde aventuras maravilhosas, como as que se encontram na Odisseia, em que a presença dos 
deuses é constante, até modernas histórias de terror, nas quais intervêm vampiros, zumbis ou fantasmas.

A literatura lida com o sobrenatural, portanto, de diversas formas, estabelecendo gêneros textuais distintos. Um desses gêneros apresenta uma condição instigante, na medida em que o acontecimento sobrenatural em si se torna objeto de discussão: 0 inusitado evento que sobreveio na narrativa aconteceu mesmo? Se aconteceu, é possível explicá-lo por meio de uma concepção racional? Ou inequivocamente se trata de um fenômeno cuja origem se situa fora do nosso plano de realidade?

Este gênero, em que o sobrenatural e suas manifestações são tratados sob o viés da dúvida, constitui o fantástico.

A dúvida costuma se avizinhar do sentimento de angústia. Muitas histórias fantásticas, com efeito, se revestem de uma forte atmosfera angustiante: febril, o personagem busca encontrar uma explicação para o que lhe sucede, nem sempre obtendo respostas satisfatórias.

Na literatura francesa, um dos autores mais propalados nesse gênero que envolve sobrenatural, dúvida e angústia foi Guy de Maupassant (1850-1893), notável contista da segunda metade do século XIX. Neste estudo, traçaremos algumas considerações sobre seus contos relacionados ao fantástico, analisando principalmente a questão do duplo, tema frequente na literatura fantástica.

Comecemos por fazer algumas breves considerações conceituais sobre o fantástico, dando ênfase principalmente às explanações de Jean Fabre, que estuda o gênero, entre outros olhares, pelo viés da antropologia. 


\section{FANTÁSTICO, MENTALIDADE ARCAICA E MENTALIDADE POSITIVA}

Aprofundado estudo sobre a literatura fantástica, a obra Le miroir de sorcière (1992), de Jean Fabre, opera com um amplo recorte temporal, além de trabalhar com uma notável diversificação de conceitos, baseados em áreas variadas tais como história, antropologia, psicanálise e teoria literária.

Ao traçar definições para o gênero fantástico, Fabre formula duas perspectivas. Na primeira, o fantástico tem um alcance histórico bem amplo, englobando a presença de um sobrenatural amedrontador que irrompe num cenário cotidiano em diversas modalidades artísticas. Na segunda abordagem, mais restrita, o fantástico se mostraria um segmento particular dessa primeira, vinculado especificamente ao século XIX, quando o sobrenatural teria ganhado um novo entendimento na civilização ocidental. Essa segunda formulação, circunscrevendo cronologicamente o gênero fantástico, é presente em importantes estudos literários, como os de Tzvetan Todorov (1970) e de Irène Bessière (1974).

Sobre Todorov, é bastante conhecido dentro das pesquisas sobre literatura fantástica o traço principal estabelecido por ele para defini-la: a hesitação. Segundo esse importante estudioso, "o fantástico é a hesitação experimentada por um ser que conhece apenas as leis naturais, diante de um evento aparentemente sobrenatural". (TODOROV, 1970, p.29) ${ }^{1}$

Assim sendo, Todorov postula que seria a hesitação, e não o medo, que caracterizaria melhor o fantástico. Embora, de fato, 1 lois naturelles, face à un événement en apparence surnaturel. [Nota: Todas as traduções do francês para o português de obras teóricas ou de passagens dos textos de Maupassant são de minha autoria.] 
muitas narrativas fantásticas se pautem no efeito de medo e terror, há um número significativo delas que não segue essa trilha poderíamos citar como exemplo os contos Véra, de Villiers de L'IsleAdam, e Magnétisme, de Guy de Maupassant.

De sua parte, Fabre considera as noções de medo e angústia fulcrais para definir o fantástico, já que esse gênero se revelaria uma expressão do mal-estar do homem na civilização. Esse mal-estar pode ser entendido se levarmos em conta uma importante circunstância que aflige o ser humano: a passagem do tempo, responsável por incutir nele a consciência de sua condição mortal.

Fabre comenta que existem dois modos elementares de se conceber a passagem do tempo: a temporalidade horizontal e a temporalidade vertical. A primeira pode ser imaginada como uma reta horizontal, formada por uma sucessão de momentos distintos entre si e seguindo uma progressão irreversível. Já a segunda se constitui de sobreposições temporais, o que pode fazê-la ser percebida como uma espécie de presente perpétuo. A irreversibilidade da passagem do tempo de acordo com a concepção horizontal se oporia, pois, ao caráter holístico da temporalidade vertical. Cada uma dessas temporalidades é responsável por gerar um tipo de visão de mundo específica: a temporalidade horizontal se associa à chamada mentalidade positiva, ao passo que a temporalidade vertical remete à mentalidade arcaica.

A mentalidade arcaica é típica das sociedades primitivas e pode ser tomada, de acordo com o que comentamos, como um mecanismo de defesa contra a angústia suscitada pela passagem do tempo, com o consequente desaparecimento das coisas e 
seres do mundo. A sobreposição de acontecimentos, que passam a ser relacionados entre si de diversas maneiras, permite que o tempo seja encarado como cíclico. Essa característica justifica a presença das diversas formas de religião e de práticas místicas na sociedade, com seus códigos morais, regras de conduta e liturgias. Além disso, e de diversas maneiras, seja através de oráculos ou de rituais específicos, o tempo futuro pode ser descortinado. E não apenas isso: o destino pode ser alterado, por pensamentos ou ações particulares.

Os diversos tipos de predições do futuro - profecias, tarô, astrologia - se baseiam, aliás, na compreensão do que se pode chamar de causalidade mágica. Esta se fundamenta no sincronismo entre fatos aparentemente sem relação entre si, o que justifica que orações e práticas ritualísticas intervenham em eventos sobre os quais o homem, segundo uma perspectiva racionalista, não teria como agir.

A mentalidade arcaica confere ao tempo e, portanto, à existência humana, uma relativa estabilidade: por mais que haja problemas e dissabores na vida, estes não provocarão o aniquilamento irrevogável do homem. O sofrimento não é senão uma fase transitória dentro da eternidade, seja para expiar faltas anteriores, seja para servir como um desafio à fé.

Bem diferente se mostra a mentalidade positiva, que entende a intervenção do homem no mundo apenas mediante o emprego de meios físicos inteligíveis. A canalização do desejo humano seja por meio de orações ou feitiçarias é considerada, portanto, inócua. Desse modo, enquanto na mentalidade arcaica sujeito e objeto 
tendem a se integrar, na mentalidade positiva essas duas instâncias se mostram claramente separadas.

Um ponto de extrema importância salientado por Fabre é que não se deve confundir racionalidade com horizontalidade. Embora o pensamento racionalista se construa a partir da mentalidade positiva, baseada na temporalidade horizontal, ele pode apresentar semelhanças com a mentalidade arcaica. As ciências, ao se desenvolverem progressivamente, fazem descobertas importantes, mas admitem lacunas em seu saber. Essa condição, ainda que decepcionante, é motivadora de novos estudos. Cada descoberta leva a um entrave que, por sua vez, mobiliza os cientistas para novas descobertas. Nesse caso, podemos falar de uma racionalidade horizontal.

Por outro lado, erguidas sobre os pilares do racionalismo, há abordagens que não admitem lacunas em seus postulados. Elas se pretendem totalizantes, no que rivalizariam com religiões e crenças sobrenaturais diversas. Proporcionando uma sensação de segurança, tal como a religião, esse tipo de perspectiva racionalista constitui um exemplo da chamada racionalidade vertical. Pensemos no emplasto Brás Cubas, descrito na obra de Machado de Assis, panaceia que prometia curar os mais variados males. E não precisamos recorrer à ficção. A publicidade, ao longo das décadas, está repleta de produtos que são de algum modo ligados à ciência e que se apresentam como verdadeiramente miraculosos, pois prometem resultados formidáveis com o mínimo esforço e em curto espaço de tempo.

De qualquer modo, espelhando uma racionalidade seja horizontal, seja vertical, a mentalidade positiva é aquela que se 
encontra em posição dominante no que diz respeito às explicações sobre o mundo físico e biológico no ocidente, pelo menos desde o século XVIII. Isso se deve especialmente à evolução das ciências e da tecnologia. Fenômenos misteriosos foram desmistificados, doenças incuráveis passaram a ser tratadas, problemas psiquiátricos ganharam um enquadramento médico em vez da abordagem espiritual, o homem conquistou mais conforto em vários âmbitos.

Isso não quer dizer, no entanto, que a mentalidade arcaica foi totalmente eliminada. As ciências trouxeram explicações e até soluções para alguns problemas, mas não para todos: o homem, afinal, ainda continua a ser vulnerável e finito.

No século XIX, época de grande entusiasmo científico, essa dualidade se mostrava bastante clara: as ciências se afiguravam como potenciais substitutas das religiões, mas não tinham como resolver todos os problemas existenciais do homem, mormente aqueles ligados à angústia por sua condição efêmera. O fantástico se desenvolve a partir dessa dupla impossibilidade de crenças, já que o sobrenatural é apresentado como superado, mas as ciências não dão conta de solucionar todos os questionamentos do ser humano. É por essa razão que esse século é considerado a era de ouro da literatura fantástica.

Nesse sentido, as ideias de Jean Fabre se aproximam das formulações de Irène Bessière, que considera o fantástico como um gênero marcado por visões de mundo contraditórias:

É preciso considerar que a narrativa fantástica não se especifica por um inverossímil único, por si só inapreensível e indefinível, mas pela justaposição e as contradições de diversos verossímeis, ou seja, 
hesitações e fraturas das convenções coletivas submetidas à prova. (BESSIÈRE, 1974, p.12)

O efeito de hesitação no fantástico não seria marcado, portanto, por um elemento tido como inverossímil, se desenvolvendo, na verdade, a partir de um feixe de visões verossímeis - arcaicas e positivas -, que se digladiam no texto, sem que o leitor se decida, pelo menos prontamente, por uma ou outra explicação. É por isso que o fantástico não pode ser reduzido à presença do sobrenatural numa história: só há fantástico se esse sobrenatural emergir num cenário realista, provocando questionamentos na leitura.

Note-se que, embora Bessière empregue a palavra "hesitação", fundamental para Todorov, sua perspectiva é mais densa. Não se trata apenas de uma indecisão de um personagem ou do leitor diante de fatos que lhe escapam à compreensão: essa hesitação é fruto da falência mútua de dois sistemas de explicação do mundo.

Fabre endossa esse ponto de vista, qualificando o fantástico como produto de uma ruptura entre as duas mentalidades já explicadas:

O fenômeno de ruptura não poderia se resumir nem a um fenômeno puramente intelectual (a "hesitação" de Todorov), nem a um fenômeno afetivo (o irracionalismo escapista dos críticos confusionistas românticos). Nem tampouco à preexistência de um sobre o outro. A ruptura se inscreve numa totalidade perceptiva cuja riqueza e coesão dependem de condições antropológicas e culturais. (FABRE, 1992, p.87) invraisemblable, de soi insaisissable et indéfinissable, mais par la juxtaposition et les contradictions des divers vraisemblables, autrement dit des hésitations et des fractures des conventions communautaires soumises à l'examen.

3 Le phénomène de rupture ne saurait ni se résumer à un phénomène purement intelectuel ("I'hésitation" de Todorov) ni à un phénomène affectif (I'irrationalisme 
Assim, conforme declara Fabre, a correta compreensão do fantástico não se atrelaria apenas a identificar determinados efeitos textuais, sejam intelectuais ou afetivos. É necessário entender de que modo o homem lida com as noções de natureza e sobrenatural. Nessa perspectiva, deve-se reconhecer que, no século XIX, embora o sobrenatural passasse a ser considerado como uma visão ingênua e superada do mundo, ele continuou a fazer parte do imaginário geral - de um modo até certo ponto parasitário, minando subrepticiamente as certezas da mentalidade positiva.

Por essa razão, Fabre acha oportuno discutir um importante artigo de Sigmund Freud sobre a literatura fantástica, chamado Das Unheimliche (publicado originalmente em 1919), o qual também é comentado por Todorov e Bessière. Nesse estudo, Freud aborda justamente aspectos superados e reprimidos da psique que estão presentes nos textos literários de teor fantástico. Especificamente no que tange aos aspectos superados, encontrarse-iam reminiscências de mentalidades arcaicas que, suplantadas por uma visão racionalista de mundo, ainda permaneceriam nos recônditos da alma humana, emergindo de modo perturbador em determinadas circunstâncias. Analisemos, então, algumas das ideias que o pai da psicanálise delineia sobre o assunto.

\section{O FANTÁSTICO E O INQUIETANTE}

Recebendo em português o título de $O$ inquietante (na tradução direta do alemão da editora Companhia das Letras), Freud elaborou um pertinente estudo para a compreensão da literatura fantástica, 
propondo esclarecer o que confere a determinadas narrativas ficcionais um aspecto de inquietação e de angústia - de unheimlich, como se diria em sua língua.

O psicanalista austríaco abre seu trabalho dando uma longa explicação semântica, baseada em dicionários, sobre as acepções do termo alemão heimlich, de difícil tradução, aliás, para as demais línguas. Sem entrar em maiores minúcias, já que Freud arrola uma série de ocorrências em que é empregado, pode-se dizer que esse vocábulo possui dois significados básicos, porém quase antônimos: sua acepção primeira seria a de representar algo "familiar", "aconchegado", ao passo que a segunda se referiria ao que é "escondido", "mantido oculto" (FREUD, 2016, p.338). Já o termo derivado unheimlich, antônimo da primeira acepção, seria bem próximo semanticamente da segunda. Considerando uma citação do filósofo Friedrich Schelling, Freud observa que unheimlich "seria tudo o que deveria permanecer secreto, oculto, mas apareceu" (FREUD, 2016, p.338).

Ele também considera, no decurso de suas explicações, que o que é novo tem potencial para gerar essa sensação de estranheza, de inquietação, enquanto o que é familiar traz normalmente uma sensação de tranquilidade. Entretanto, nem tudo que é novo se mostra inquietante; e, em contrapartida, determinados elementos familiares, bem conhecidos, podem vir a sê-lo. A questão central desse estudo de Freud seria, pois, determinar o que se agrega a algo familiar tornando-o ameaçador, inquietante. Ele discorre sobre o tema analisando aspectos da vida prática e também das narrativas literárias. 
Recorrendo a um estudo feito anteriormente, em 1906, intitulado Zur Psychologie des Unheimlichen, Freud apresenta a hipótese traçada pelo médico psiquiatra Ernst Jentsch, que atribuía à sensação inquietante, provocada por determinadas obras de literatura, uma incerteza intelectual por parte do leitor diante dos acontecimentos relatados, nisso se aproximando da definição que décadas depois seria formulada por Todorov. Jentsch ilustra suas ideias analisando o conto O Homem da Areia (1815), do alemão Ernst Hoffmann. Nessa história, o protagonista Nathaniel se apaixona por Olímpia, que o leitor não sabe exatamente se é uma mulher ou um manequim de madeira.

Todavia, Freud não concorda com a hipótese traçada por Jentsch. O que conferiria à trama elaborada por Hoffmann um caráter de inquietação não seria a dúvida acerca da real identidade de Olímpia. De acordo com Freud, a conclusão da narrativa desfaz a ambiguidade sobre a natureza de alguns eventos contados - mas não faz cessar, ainda assim, seu traço inquietante. Este residiria, na verdade, na presença intimidadora do Homem da Areia, figura legendária que pune as crianças que se recusam a dormir na hora estipulada jogando-lhes areia nos olhos e, em seguida, arrancandoos, a fim de levá-los como alimento para seus filhos.

O sentimento de medo e angústia suscitado por esse ente medonho não é provocado, contudo, diretamente pela retirada dos olhos: o impacto se daria pelo significado inconsciente desse ato, que aponta para a ansiedade infantil gerada pelo complexo de castração. Freud sustenta essa opinião respaldado por seus estudos de sonhos, fantasias e mitos (FREUD, 2016, p.347). 
No decorrer de seu artigo, Freud pondera que as sensações de inquietação efetivamente vivenciadas pelo homem não coincidem exatamente com as produzidas por obras literárias. As narrativas ficcionais forjam o inquietante em situações em que na prática ele não existiria e, de modo inverso, o eliminam quando ele poderia irromper.

Nesse segundo caso, Freud fala de histórias em que o sobrenatural se configura sem questionamento algum, dentro de uma normalidade. Sem essa atmosfera de questionamento não haveria estranhamento nem inquietação - em termos conceituais não estaríamos dentro do fantástico, mas sim de outro gênero, o maravilhoso.

Por outro lado, o mestre austríaco ressalta o poder criativo da literatura ao comentar que há narrativas que constroem traços inquietantes que não se veriam na vivência prática: isso ocorre porque o escritor manipula o texto de tal forma que a leitura é guiada muitas vezes através dos atos e dos pensamentos dos personagens.

Para exemplificar essa faculdade do texto literário, voltemos ao conto $O$ Homem da Areia. Freud, já comentamos, não considera que o teor inquietante desse texto se encontre na dúvida acerca da natureza de Olímpia - mulher ou boneca? Ressaltando, sobretudo, um outro aspecto, que seria o complexo de castração relacionado ao Homem da Areia, Freud minimiza, assim, o questionamento sobre Olímpia. Para ele, tal assunto não é intrinsecamente inquietante. É comum que crianças tenham dúvida se bonecos são seres vivos ou inanimados; e, mais do que isso, seria possível admitir que ver bonecos ganharem vida constituiria um aspecto de desejo, e não de medo, para muitas delas. 
O medo e o inquietante seriam experimentados principalmente por adultos que, tendo assimilado há muito que bonecos são definitivamente seres inanimados, viessem a ter dúvidas sobre sua natureza. Nesse caso, haveria o retorno de crenças tidas como superadas.

Existiriam, então, para o mestre austríaco, dois tipos de inquietante. Embora tenham um traço em comum, que é o de se associarem à infância, poderíamos distingui-los nos seguintes termos: um se relacionaria a impulsos infantis reprimidos, entre os quais o já citado complexo de castração; o outro, por sua vez, se basearia em crenças animistas superadas, caso dos bonecos que ganham vida através do desejo. Essas crenças animistas podem ser consideradas expressões de um certo narcisismo e se relacionam à atribuição de poderes ao pensamento, a coisas, a pessoas e a rituais. Levando em conta as explicações de Jean Fabre que já comentamos, tais crenças seriam exemplos da chamada mentalidade arcaica. Sobre elas, Freud afirma o seguinte:

Parece que todos nós, em nossa evolução individual, passamos por uma fase correspondente a esse animismo dos primitivos, que em nenhum de nós ela transcorreu sem deixar vestígios e traços ainda capazes de manifestação, e que tudo o que hoje parece "inquietante" preenche a condição de tocar nesses restos de atividade psíquica animista e estimular sua manifestação. (FREUD, 2016, p.359)

Desses dois tipos de inquietante, teríamos uma gama de situações que, na vida real ou na literatura, Ihes seriam vinculados: desejos que se cumprem, repetições diversas, coincidências, coisas relacionadas à morte, medo de ser enterrado vivo ou de ter 
membros do corpo cortados. No que tange a aspectos superados da mentalidade arcaica, há um elemento específico que, na realidade, constitui por si só uma rede temática: o duplo.

Inicialmente constituindo uma resposta reconfortante à possibilidade de desaparecimento total do homem depois da morte, o primeiro exemplo de duplo, presumivelmente, é a alma, contraparte imortal do corpo perecível. Tal concepção se origina do amor a si próprio, isto é, de um sentimento narcisista, normal na vida psíquica da criança e também na do homem primitivo. No entanto, essa noção do duplo não desaparece no decorrer do desenvolvimento humano, quando esse narcisismo inicial é superado. Segundo Freud, forma-se lentamente uma instância de auto-observação e autocrítica sobre o resto do Eu, que efetua um trabalho de censura (FREUD, 2016, p.353). Em casos patológicos, como nos delírios de perseguição, essa instância se torna isolada, dissociando-se do Eu.

O tema do duplo na literatura não se manifesta apenas através do personagem sósia, extremamente parecido, ou mesmo idêntico, ao protagonista da trama. Freud menciona uma tipologia ampla: a ligação psíquica, incluindo aí a telepatia (um personagem sabe muito sobre a mente do outro); a identificação profunda de um personagem para com outro, a ponto de ele duvidar de sua própria identidade; e o retorno de determinadas características entre personagens de diferentes gerações (repetição de nomes, de traços físicos e / ou psicológicos, de acontecimentos).

Em vários contos de Guy de Maupassant, o duplo realmente se manifesta de diversas formas que, invariavelmente, conferem 
ao texto uma sensação inquietante. Analisemos algumas das narrativas em que isso ocorre, sublinhando a diversidade de suas manifestações. Essas expressões do duplo, veremos, podem ser relacionadas à própria natureza das narrativas curtas do século XIX.

\section{O DUPLO E O INQUIETANTE EM MAUPASSANT}

Até o momento, referimo-nos a Guy de Maupassant como contista. No entanto, dentro da nomenclatura literária, ao se falar de narrativas curtas, há uma imprecisão de emprego entre os termos "conto" e "novela" em língua portuguesa, assim como existe entre conte e nouvelle, em francês. O exame mais apurado desses termos representaria um trabalho à parte, já que demandaria considerações diacrônicas, sem contar inúmeras ressalvas de ordem linguística, visto que cada tradição nacional oferece significados diversos para ambos.

Na prática, em português o termo mais usado para se falar de narrativas curtas é "conto", englobando aí tanto histórias folclóricas e tradicionais quanto tramas realistas, de maior cunho criativo. Em francês, conte e nouvelle também se intercambiam, mas este último termo parece mais usado que seu correspondente em português. Haveria uma tendência, sujeita a diversas flutuações, de se empregar conte para designar histórias folclóricas e maravilhosas, enquanto nouvelle seria o termo reservado para as tramas realistas. Ainda dentro da língua francesa, é comum tanto a expressão contes fantastiques quanto nouvelles fantastiques. Narrativas desse tipo não se confundiriam com as histórias maravilhosas, nas quais o sobrenatural não provoca questionamentos: o fantástico, deve-se frisar, representa uma fronteira imprecisa do realismo, por se tratar de uma experiência de limites da percepção subjetiva. 
As considerações feitas anteriormente não constituem uma mera curiosidade terminológica. Em um importante estudo sobre o gênero nouvelle, Thierry Ozwald defende a tese de que esta é um produto eminente do século XIX, porque é nesse período, com poucas exceções anteriores, que se acham narrativas curtas com duas características particulares: a preocupação realista e a dramatização crítica.

O primeiro item, ao contrário do que possa parecer, não representa uma categoria objetiva, mas um olhar subjetivo da realidade: segundo Ozwald, o realismo, desmentindo determinadas noções preconcebidas, não postula a existência de uma realidade estável ou de um mundo dado a priori. Uma amostra representativa dos textos que estudou apontaria para um realismo que se constrói a partir de um mundo turbulento, que parece fugir da compreensão do personagem (OZWALD, 1996, p.35).

Já a dramatização crítica consistiria na progressão da narrativa visando desde seu início um desfecho negativo para o personagem, sendo desencadeada pelo rompimento de uma situação inicial de equilíbrio e com as ações girando em torno de um eixo único. Com frequência, os personagens experimentam um desfecho melancólico ou trágico.

O que Ozwald entende como nouvelle é uma narrativa particularmente fenomenelógica, que expressaria a busca frustrada do sujeito por uma verdade (OZWALD, 1996, p.16). A nouvelle representa, assim, um índice de fragmentação da consciência subjetiva, relacionada intimamente ao século XIX. Lembremonos que esse período é marcado por profundas modificações 
sociais (depois da Revolução Francesa e no decurso da Revolução Industrial), pela ascensão do cientificismo, bem como pela relativa perda de influência da religião e da espiritualidade.

Assim consideradas, as nouvelles se distinguiriam de outras modalidades de narrativas curtas, entre as quais poderíamos citar os contos tradicionais, os fabliaux e as novelas do tipo Decamerão. Essas modalidades apresentam uma progressão não linear, mas sim cíclica, com o desfecho precedendo o final da trama, o que propicia a instalação de uma nova situação de equilíbrio, similar à original. São frequentes os finais com lições moralizantes, situação que não se costuma ver nas nouvelles do século XIX, nas quais o personagem frequentemente se encontra desamparado e desnorteado no mundo.

Muito teríamos a comentar acerca das ideias de Ozwald, mas restringimo-nos ao seguinte ponto de vista: o de que mesmo as nouvelles mais evidentemente realistas, pelo fato de apresentarem uma realidade instável, apreendida por uma consciência individual em crise, se mostram fortemente aparentadas ao fantástico. Ou dito de outra forma: que não haveria uma distinção de natureza entre realismo e fantástico, senão de grau, já que ambos fariam parte de um mesmo continuum.

Essa perspectiva concede à questão do duplo, signo da fragmentação do sujeito segundo Ozwald, uma grande importância na composição das narrativas curtas, sejam eminentemente realistas, sejam fantásticas. O duplo, conforme já demonstramos ao mencionar Freud, não se resume à presença de um ser idêntico a outro, podendo na realidade se apresentar de maneiras diversas. Um dos elementos que Ozwald aponta como expressão do duplo se relaciona à própria estrutura narrativa, que por vezes se processa 
de modo dual: um evento parece se repetir, mas apresentando certas diferenças que imprimem à narrativa um caráter inquietante e, ao personagem, um destino desalentador.

O estudo de algumas narrativas de Maupassant pode ilustrar essa estrutura dual, bem como a manifestação de outras formas do duplo. Focaremos nossa análise em alguns de seus contos fantásticos, nos quais, presumivelmente, o duplo se configura de maneira mais notável.

\section{A PROGRESSÃO NARRATIVA DUPLICADA}

A presença do duplo nos textos de Maupassant se mostra sabidamente frequente, conforme atestam inúmeros trabalhos sobre o autor francês. Um aspecto interessante, todavia, é estudar o duplo enquanto replicação de parte do fluxo narrativo: determinados eventos retornam na progressão da história, mas não numa repetição perfeita. São essas diferenças entre as cenas, impedindo que se configurem como reflexos perfeitos uma da outra, que geram o inquietante. A esse respeito, vale lembrar que Freud considera a repetição um potencial desencadeador de reações inquietantes, mas não a vincula ao duplo, como uma subespécie deste, embora sejam temas aparentados. Em nossa proposta, baseando-nos nos conceitos de Thierry Ozwald, assumimos a repetição como uma expressão do duplo e elemento decisivamente estruturador do fluxo dual da narrativa. Vejamos como essa dualidade narrativa se configura em alguns contos de Maupassant.

Em Le docteur Héraclius Gloss, um dos primeiros contos escritos pelo autor normando, o personagem homônimo é internado por duas vezes no hospício. Essa repetição marca, todavia, dois instantes 
substancialmente diferentes. Na primeira internação, Héraclius Gloss mostrava-se entusiasmado pela ideia da metempsicose. Essa crença se baseia na passagem da alma, após a morte, para outro corpo. Ela corresponde ao que se conhece habitualmente como reencarnação, mas tendo uma especificidade: diferente do conceito reencarnatório mais divulgado no ocidente, de acordo com a metempsicose a alma de um ser humano pode voltar no corpo de um animal. Gloss é levado para o hospício justamente porque propõe que seres humanos e animais devam ser tratados da mesma maneira, posição que o faz ser considerado insano: de certa feita, ao ver um grupo de meninos apedrejarem um gato que estava para se afogar, o doutor investe contra eles, salva o felino, mas derruba um dos meninos na água, que só se salva porque é resgatado por dois marinheiros.

Gloss, é verdade, recebe alta após essa internação. Contudo, ele não volta a uma situação de normalidade. Ao retornar a sua casa e rever os vários animais que lá se encontram, e com os quais ele lidava como se fossem humanos reencarnados, o doutor tem um surto e tenta matar todos eles. Desse modo, ele é novamente internado no hospício, mas agora com uma diferença: sua detenção parece ter caráter irrevogável. A crença na metempsicose, que antes o arrebatava como uma abordagem capaz de tornar a realidade inteligível, é destroçada. O encerramento da história marca o fim de sua possibilidade de se harmonizar com o mundo. $\mathrm{O}$ evento da ida ao hospício tem, pois, um duplo, que não lhe é, todavia, idêntico. E é nessa diferença que o personagem se desencaminha.

Essa narrativa possui ainda outros temas do duplo. Em primeiro lugar, a própria metempsicose já evoca essa noção, uma vez que se 
baseia na transmigração da alma, duplo do corpo físico. Em segundo lugar, desenrola-se em parte da trama o tema do rival e do duelo, os quais muitas vezes se associam ao duplo. Nesse caso, o rival de Héraclius Gloss é Dagobert Félorme, um dos pacientes do asilo de loucos, a quem encontra quando de sua primeira internação. Gloss tornara-se adepto da metempsicose ao achar, por acaso, um manuscrito pretensamente datado do ano 184, que falaria das sucessivas vidas do sábio grego Pitágoras.

O referido manuscrito impressionou Gloss de tal forma que ele não apenas passou a dispensar aos animais o mesmo tratamento que dava aos seres humanos, como acreditou ser o próprio Pitágoras reencarnado! Todavia, ao confrontar Dagobert Félorme, que tinha ideias similares, Gloss fica perplexo: Félorme sabe de tudo o que o manuscrito contém, o que o leva a concluir que foi o outro interno que o redigira. Dessa maneira, o sólido edifício de convicções de Héracliuss Gloss desaba estrepitosamente: o sistema doutrinário que lhe explicava o mundo nada mais era do que o delírio de um doente mental.

Cabe aqui, ainda, uma observação: a doutrina da metempsicose não constitui uma descoberta científica, uma vez que já era partilhada por diversos povos desde épocas recuadas. No entanto, Gloss a reveste de um valor racional, pois, segundo ele, ela seria mais lógica que a teologia cristã, que concebe o pós-morte fundamentalmente em termos de céu e inferno - e também de purgatório na doutrina católica. Teríamos então uma antiga crença revitalizada pela razão, mas sem perder o seu caráter totalizante e mesmo apaziguador, típico das religiões. Isso se configuraria como um exemplo da racionalidade vertical, sobre a qual já traçamos 
alguns comentários. O caráter de interseção entre mentalidade arcaica (a metempsicose em si) e mentalidade positiva (sua atualização enquanto sistema racional), reconfortante numa dada etapa da narrativa, se esfacela, acarretando um desfecho negativo para o personagem, que termina a trama num hospício.

Outro conto em que a estrutura narrativa se apresenta de modo dual por conta de um traço de repetição é Histoire d'un chien, história que veio a ser republicada numa versão quase idêntica sob o título Mademoiselle Cocotte. O personagem François, que trabalhava como cocheiro para uma família em Paris, afeiçoou-se por uma cachorra que teimava em segui-lo, à qual deu o nome de Cocotte. Fazendo dela seu animal de estimação, François chegou mesmo a lhe dar uma coleira com uma placa de cobre contendo a inscrição "Senhorita Cocotte, do cocheiro François".

O animal, contudo, trouxe vários problemas para a casa dos patrões de François, porque, estando no cio, ela atraía inúmeros cães. O patrão solicitou que a cadela fosse mandada embora, e François tentou cumprir esse pedido, mas sem sucesso, já que Cocotte retornava para junto do dono. A paciência do patrão, então, se esgotou, e ele ordenou que François a afogasse no rio Sena, que passava perto da luxuosa casa em que vivia em Paris.

Com o coração partido, François levou Cocotte até as margens do rio, amarrou-Ihe uma pedra no pescoço e lançou-a em suas águas. O cocheiro, alquebrado, observou-a se debater desesperadamente, vindo, pouco depois, a sumir em definitivo sob as águas. 0 choque psíquico experimentado por François foi bastante severo; abalado, ele sonhava com a cachorra todos os dias e julgava até ouvir seu latido. 
Durante cerca de um mês, François permaneceu com o comportamento pesarosamente alterado. Melhorando um pouco, foi levado por seus patrões a uma propriedade que tinham em Rouen. Lá, sua recuperação pareceu se tornar mais evidente, graças, entre outras coisas, aos banhos e à natação que fazia nas águas do Sena, que também passava naquela região.

Um dia, no entanto, François percebeu algo de diferente flutuando no rio. Ao se aproximar, assustou-se: parecia ser o esqueleto de um cão. Horrorizado, o cocheiro ficou atônito ao descobrir nesse corpo já em decomposição a placa com a inscrição que fizera para a cadela Cocotte. O choque lhe fora então tão violento que ele enlouqueceu, vindo a ser internado num hospício.

Tanto Histoire d'un chien quanto Mademoiselle Cocotte costumam figurar em coletâneas de contos fantástico de Maupassant. Embora não haja nessa trama um sobrenatural explícito, a improbabilidade exposta em suas páginas é inquietante: François, como que recebendo um castigo, revê o corpo da cachorra a quem matara muitos quilômetros além de onde a afogou, e mais de um mês depois. Nesse caso é a ida ao rio Sena o elemento que duplica a estrutura narrativa, duplicação esta que mais uma vez sinaliza a derrocada de um personagem.

Outro exemplo marcante dessa estrutura narrativa dual é a segunda versão de Le Horla, que segue a forma de um diário. Podese traçar o seguinte esquema, dividido em duas partes. Na primeira, vemos que as indicações entre o dia 8 de maio e o dia 3 de junho mostram a progressão de um estado de angústia experimentado pelo personagem que, inicialmente tranquilo, passa a se sentir 
paulatinamente nervoso, como que ameaçado por algo que ele não consegue explicar. Há um hiato de alguns dias entre as notas do diário, já que o personagem decide fazer uma viagem para se aquietar. $\mathrm{O}$ dia 2 de julho marca uma segunda fase da narrativa, sinalizando a repetição de um estado de placidez: o personagem naquela altura se julga curado. Comparemos as descrições feitas nessas duas datas:

8 de maio - Que dia admirável! Eu passei a manhã toda estendido na grama, diante de minha casa, sob o enorme plátano que a cobre, a abriga e a sombreia inteira. Eu gosto dessa região, e gosto de viver aqui porque aqui tenho minhas raízes, raízes profundas e delicadas, que ligam um homem à terra em que nasceram e morreram seus antepassados. (MAUPASSANT, 1957. p.1097, vol.2) ${ }^{4}$

2 de julho - Eu retorno. Estou curado. Eu fiz, aliás, uma excursão fascinante. Eu visitei o monte SaintMichel que eu não conhecia.

Que visão quando se chega lá, como eu em Avranches, por volta do final do dia! (MAUPASSANT, 1957. p.1101, vol.2) ${ }^{5}$

Os dois trechos anteriores mostram não apenas serenidade, como também uma certa alegria, evidenciada inclusive pelo uso de pontos de exclamação. Porém, depois do dia 2 de julho, os transtornos nervosos do personagem voltam, e ainda mais intensos: ele se crê vítima de uma entidade invisível que o obsedia, um ser

48 mai. - Quelle journée admirable! J'ai passé toute la matinée étendu sur l'herbe, devant ma maison, sous l'énorme platane qui la couvre, l'abrite et l'ombrage tout entière. J'aime ce pays, et j'aime y vivre parce que j'y ai mes racines, ces profondes et délicates racines, qui attachent un homme à la terre où sont nés et morts ses aïeux 52 juillet - Je rentre. Je suis guéri. J'ai fait d'ailleurs une excursion charmante. J'ai visité le mont Saint-Michel que je ne connaissais pas.

Quelle vision, quand on arrive, comme moi à Avranches, vers la fin du jour! 
que, similar a um fantasma, representaria na realidade uma nova etapa da evolução humana.

A última data registrada no diário é 10 de setembro e também contém um ponto de exclamação, porém transmitindo uma sensação de pavor, não mais de alegria. Esse ponto de exclamação é acompanhado de reticências, que evidenciam o desespero por que passa o personagem. Este tenta atacar o amedrontador inimigo, chamado por ele de Horla, mas acredita não ter sucesso, razão pela qual irrompe em sua mente a trágica opção pelo suicídio: “Não... não... sem nenhuma dúvida, sem nenhuma dúvida... ele não morreu... Então... Então... vai ser preciso que eu mesmo me mate!" (MAUPASSANT, 1957. p.1123, vol.2) ${ }^{6}$

Além da duplicação narrativa, encontramos nessa trama outra expressão do duplo, que é, evidentemente, o próprio ser denominado Horla. Vimos que o duplo inicialmente representava uma entidade tranquilizadora: poderia ser tanto a própria alma da pessoa, como seu anjo da guarda, por exemplo. Na visão cientificista de Maupassant, a crença tradicional de espíritos muitas vezes é reinterpretada: no caso dessa história, o texto nos faz crer que o personagem não se defronta contra um espírito ou um demônio, mas sim contra um ser mais evoluído, com faculdades além das presentes no homem. Verificamos, portanto, que a ideia de evolução das espécies, manifestação da mentalidade positiva, pode parecer tão ameaçadora quanto determinados aspectos de crenças religiosas, como os ligados à existência de entidades malévolas.

6 Non... non... sans aucun doute, sans aucun doute... il n'est pas mort... Alors... Alors... il va donc falloir que je me tue, moi!... 
Nas duas versões de Le Horla, esse misterioso ser é notado de início de modo vago; em seguida, aparecem evidências de que há algo de concretamente estranho acontecendo, como os copos de água e de leite que amanhecem consumidos, a flor que levita em pleno ar e as páginas de um livro que se viram sozinhas. A prova incontestável da existência dessa entidade se dá pelo espelho e, curiosamente, por uma não visão: o personagem se detém diante de um espelho, buscando naturalmente ver seu reflexo nele, mas nada aparece, sequer seu rosto, como se houvesse algo invisível interposto. A sequência das duas versões dessa história é desfavorável para o protagonista: na primeira, ele termina num hospício; na segunda, conforme vimos, dá-se a entender que ele comete suicídio.

Tendo em base as análises anteriores, notamos que um considerável número de contos de Maupassant termina com o personagem internado num asilo de loucos. A esse respeito, cabe dizer que o escritor francês se interessava pelos estudos psiquiátricos de sua época, tendo inclusive assistido a cursos com o médico JeanMartin Charcot, que foi professor de Sigmund Freud. Sua biografia foi marcada por problemas nervosos, tendo sido acometidos por esses males também sua mãe e seu irmão.

Sem recorrermos a maiores digressões biográficas sobre Guy de Maupassant, parece evidente a correlação entre fantástico e loucura, até em razão dos temas abordados, que apontam não raro para uma discussão acerca das noções de consciência e realidade. Sob esse aspecto, mostra-se importante apreciarmos as manifestações do duplo que expressam traços latentes da personalidade humana. 


\section{O DUPLO E OS ASPECTOS OCULTOS DA PERSONALIDADE}

Seguindo as ideias de Freud, Marie-Claire Bancquart considera que o duplo nas obras de Maupassant nunca representa uma cópia exata de um personagem. Por esse motivo, ela usa a expressão "duplo distanciado" (double décalé) para caracterizar esse elemento das tramas do autor francês (BANCQUART, 1976, p.33).

Pode-se citar como exemplo de manifestação do duplo o lado obscuro e cruel que alguns personagens possuem, não obstante gozarem de ilibada reputação nas comunidades que frequentam. $\mathrm{O}$ prefeito Renardet, do conto La petite Roque, se enquadraria nessa situação: ele comanda as investigações acerca do assassinato de Roque, violentada e morta na verdade por ele mesmo. Nessa trama, o espírito de Roque costuma lhe aparecer, resultando num processo de perturbação tal que Renardet recorre ao suicídio para se livrar desse tormento psicológico. O comportamento de Renardet é, aliás, dual: responsável por violentar e matar não apenas Roque, mas também outra adolescente, ele se mostra abatido por remorsos, processo que culmina no atentado contra a própria vida.

Em Un fou?, o duplo se traduz no misterioso poder que permite ao personagem Jacques Parent controlar seres inanimados e até animados com a ação da mente. Essa peculiar faculdade, atribuída ao magnetismo animal, crença corrente no século XIX, em vez de Ihe conceder orgulho ou satisfação, Ihe provoca medo, já que ela parece pertencer a outro ser, o qual poderia controlá-lo:

Quanto a mim, eu sou dotado de um poder amedrontador. Poderíamos dizer um outro ser aprisionado em mim, que quer incessantemente escapar, agir contra minha vontade, que se agita, 
que me consome, que me esgota. Quem é ele? Não sei, mas nós somos dois no meu pobre corpo, e é ele, o outro, que é quase sempre o mais forte [...] (MAUPASSANT, p.973, vol.2) ${ }^{7}$

Poderíamos inferir daí que o duplo pode ser representado pela vontade de manipular o outro, sem as amarras de códigos éticos e morais. Observe-se ainda que, nessa trama, temos um claro exemplo de mentalidade arcaica superada que retorna à consciência: tratase da crença do que Freud chama de "onipotência do pensamento", associada a uma visão animista do mundo (FREUD, 2016, p.359).

Outro elemento que se encarregaria de cumprir a função do duplo é o medo, visto como se fosse uma cisão na personalidade. No conto Sur l'eau, o protagonista conta como em certa ocasião testemunhou um singular evento: um nevoeiro demasiadamente espesso que acabou por cobrir apenas as margens do Sena, à semelhança de dois espantosos e altíssimos muros. Ao narrar esse fato, ele explica a sensação de medo que experimentou, como se fosse uma sensação de outra pessoa incorporada nele:

Eu sentia a firme vontade de não ter medo, mas havia em mim outra coisa além de minha vontade, e essa outra coisa sentia medo. Eu me perguntei o que eu estava temendo; mas meu eu corajoso censurou meu eu covarde, e nunca tanto como naquele dia eu percebi a oposição de dois seres que estão em nós, um querendo, o outro resistindo, e cada um predominando alternadamente. (MAUPASSANT, 1957, p.773, vol. 2) ${ }^{8}$

7 Quant à moi, je suis doué d'une puissance affreuse. On dirait un autre être enfermé en moi, qui veut sans cesse s'échapper, agir malgré moi, qui s'agite, me ronge, m'épuise. Quel est-il? Je ne sais pas, mais nous sommes deux dans mon pauvre corps, et c'est lui, l'autre, qui est souvent le plus fort, comme ce soir.

8 Je me sentais la volonté bien ferme de ne point avoir peur, mais il y avait en moi autre chose que ma volonté, et cette autre chose avait peur. Je me demandai ce 
No conto La Morte, também se explora o lado obscuro da personalidade, mas sob um outro ângulo, pois, nessa história, o duplo a se revelar não é o do protagonista, mas sim o de sua companheira. Nesse conto, um desalentado personagem, abatido pela morte da namorada, vitimada por pneumonia, decide passar uma noite no cemitério, ao lado da tumba da falecida.

De súbito, ele se surpreende ao ver os esqueletos levantarem de seus túmulos e reescreverem com os ossos dos dedos os respectivos epitáfios. Aos textos generosos que lhe foram dedicados, os defuntos sobrescrevem mensagens de sincera confissão: é assim que frases delicadas como "Amou os seus e foi respeitado" dão lugar a sentenças ácidas do tipo "Torturou a esposa e atormentou os filhos". O personagem da trama fica ainda mais atônito quando vê a mudança que sua amada efetuou: a inscrição original, de responsabilidade dele próprio, "Ela amou, foi amada e morreu", é descartada em prol da chocante "Saindo um dia para trair seu namorado, ela pegou resfriado por causa da chuva e morreu" (MAUPASSANT, p.1136-1137, vol.2).

Deve-se mencionar, ainda, um sentimento frequente nas narrativas do escritor normando que também ganha o relevo de duplo: a solidão. Um dos contos que melhor ilustra esse enfoque, chegando mesmo à personificação, é Lui?, história que se desencadeia a partir da conversa de um personagem com um amigo, a quem informa sobre seu casamento. A franqueza do protagonista se mostra desconcertante, já que ele declara que pouco conhece da futura esposa, que continua sendo contra o matrimônio e, o mais que je pouvais redouter; mon moi brave railla mon moi poltron, et jamais aussi bien que ce jour-là je ne saisis l'opposition des deux êtres qui sont en nous, l'un voulant, l'autre résistant, et chacun l'emportant tour à tour. 
surpreendente, que é incapaz de amar uma mulher, pois sempre foi a favor das relações livres. O motivo para o casamento, contudo, se mostra bem claro: o medo de ficar sozinho.

O protagonista justifica sua decisão matrimonial narrando ao amigo um estranho fato que Ihe aconteceu meses antes. Um dia, ao chegar a casa, como sempre fazia, o personagem experimentou uma terrível sensação de angústia, relacionada ao vazio de sua casa. Achando-se sufocantemente sozinho, ele decide sair para ver algum amigo. Procura por três deles, mas sem sucesso. Decide então voltar para casa, quando, ao entrar, percebe que a porta não está trancada, como sempre deixa, mas apenas encostada. Essa sensação de estranheza o perturba, mas ele tenta se tranquilizar, especulando que a zeladora poderia, com uma chave reserva, ter aberto a porta para um amigo. Ao vasculhar a casa, o personagem tem um choque: ele nota que há alguém deitado em sua poltrona, com o braço pendendo para fora, os pés cruzados um sobre o outro, e a cabeça inclinada. Ao se aproximar para lhe tocar o ombro e acordar essa pessoa, o personagem simplesmente não a vê mais! Ele procura depois se acalmar, considerando que talvez tenha sonhado ou mesmo tido uma alucinação. O fato é que, andando pela casa, ele julga ver de novo o misterioso homem numa fração de segundos, sumindo em seguida. Por duas vezes durante o sono, o personagem experimenta a inquieta sensação de não estar sozinho. E essa sensação torna-se habitual: ele crê que a qualquer momento pode voltar a ver o estranho visitante.

$\mathrm{O}$ angustiado homem em momento algum aventa a hipótese de presença sobrenatural. Porém, mostra-se tão amedrontado como se o homem visto fosse um fantasma: 
Eu estava com medo de revê-lo. Não medo dele, não medo de sua presença, na qual eu não acreditava de modo algum, mas eu estava com medo de um distúrbio dos meus olhos, medo de uma alucinação, medo do pavor que me subjugaria (MAUPASSANT, 1957, p.858, vol.2) $^{9}$

O personagem está certo de que essa visão voltará a acontecer. E se convence de que, só deixando de morar sozinho, poderia voltar a ter paz, motivo pelo qual decide se casar. Note-se que um estranho e forte sentimento de solidão precede a misteriosa aparição. Esta talvez represente um aspecto paradoxal de sua mente: ao mesmo tempo em que não quer ficar sozinho, o personagem teme que o visitante represente um transtorno de percepção da realidade, o início de um processo de loucura. Também se deve levar em conta que Freud, no final de seu artigo $O$ inquietante, afirma que circunstâncias tais como silêncio, solidão e escuridão se associam a uma angústia infantil que, em muitas pessoas, não desaparece totalmente (FREUD, 2016, p.376) no decorrer da vida.

Por fim, é necessário tecer mais uma ponderação. Do mesmo modo que em outros autores, o duplo em Maupassant, sob qualquer forma - duplicação narrativa ou representação de aspectos psíquicos variados - se mostra ameaçador e provocador de sentimentos inquietantes, muitas vezes levando personagens para desfechos nefastos. Em nossa experiência como leitor e analista do autor, em nenhum texto dele observamos a presença de um "duplo do bem", ou seja, alguma cisão da personalidade humana que pudesse se mostrar apaziguadora.

9 J'avais peur de le revoir, lui. Non pas peur de lui, non pas peur de sa présence, à laquelle je ne croyais point, mais j'avais peur d'un trouble nouveau de mes yeux, peur de l'hallucination, peur de l'épouvante qui me saisirait. 
Contudo, há que se ressaltar uma narrativa em que o duplo, como de hábito, não se mostra amigável, mas tem sua influência perniciosa suplantada. Ela nos chamou a atenção por ser, no universo de textos de Maupassant sobre os quais nos detivemos uma das únicas que se encerra com um final favorável ao personagem destacado, merecendo por isso considerações à parte (MOREIRA, 2001, p.184). Estamos falando do Conte de Noël, história que narra um presumível caso de possessão demoníaca após uma mulher ter consumido um ovo que estranhamente fora achado na neve. Essa história, à semelhança de outros contos fantásticos do autor, apresenta uma duplicação da estrutura narrativa: em dois momentos a mulher é submetida a uma cerimônia de exorcismo, uma vez um pouco antes do natal, a outra vez exatamente na noite natalina. Nessa segunda oportunidade, diferente do insucesso da primeira tentativa, o padre teve êxito na medida em que julga que expulsou o espírito maligno que teria possuído a mulher, ao lhe mostrar o ostensório, em meio à missa de natal, repleta de fiéis.

O final da história não se fecha sobre uma interpretação única do que acontecera. O padre tem certeza de que houve mesmo uma possessão e que, posteriormente, o ritual católico, invocando o poder de Jesus Cristo, fora o responsável por libertar a vítima dessa influência maligna. Por outro lado, o médico, doutor Bonenfant, que fora consultado, prefere achar que o exorcismo não representou um evento sobrenatural, mas apenas um procedimento de alto grau de sugestão. Foi por ter expectativas na influência psicológica desse ritual que Bonenfant de bom grado aceitou que a mulher lhe fosse submetida. De qualquer modo, o médico trata esse acontecimento 
como uma bela lembrança de natal e o considera mesmo um milagre-porque, embora ele não acredite em instâncias espirituais, reconhece que a fé é um sentimento poderosíssimo, capaz de alterar situações ao redor.

Talvez essa história, que contém um final feliz, marque a nostalgia de uma época em que a crença religiosa era reconfortante para a maioria das pessoas. Ou que essa nostalgia tangencie também determinados valores sociais tradicionais como os da família. Diferente de outras narrativas em que o protagonista é uma pessoa solitária, nesta a mulher possuída tem uma família e, no momento da missa, não apenas seus familiares estão presentes, bem como a comunidade local em peso. Assim, seria plausível supor que a presença de entidades coletivas (família e comunidade) tenha estabelecido um vínculo de união para com a mulher, que se contrapõe à cisão típica do duplo.

A figura do diabo costuma ser associada à divisão e à discórdia, características compatíveis com a do duplo. O ritual na igreja, por outro lado, representa uma união, uma unificação - entre os fiéis entre si, e destes com Deus. Nesse caso, é a unificação que saiu vitoriosa em seu confronto contra a fragmentação que o duplo provoca.

\section{CONSIDERAÇÕES FINAIS}

O duplo, com seu vasto domínio temático, é, de acordo com Freud, um dos elementos de que os escritores se servem para desenvolverem em seus textos o sentimento de unheimlich - o inquietante, o estranhamento a coisas que até um dado momento eram familiares. 
Uma quantidade substancial de contos de Guy de Maupassant, realistas e fantásticos, é marcada pela presença do duplo, que se manifesta sob diversas formas: na própria estrutura narrativa duplicada ou como representação de diversos aspectos da psique, sejam desejos insidiosos, sejam sentimentos angustiantes tais quais medo e solidão.

De acordo com Freud, muitas situações criadas pelos autores literários para conferir inquietação ao texto remetem a duas condições que se atrelam à infância: a superação de determinadas crenças e a repressão de certos impulsos (neste segundo caso, Freud dá o exemplo do complexo de castração). No que diz respeito ao duplo, seu inquietante se vincula em geral a crenças superadas que, em determinadas situações, são reativadas. É esse movimento de reativação de uma crença julgada como inconsistente que pode provocar o efeito de inquietante no texto, a partir dos focos dados a situações e personagens conforme as técnicas empregadas por cada autor. Textos de Maupassant como Lui?, Un fou? e Le Horla são emblemáticos desse retorno das crenças superadas, associadas uma visão animista da realidade. Em outros textos, o duplo parece ter um caráter mais simbólico, como em Sur l'eau, em que a alternância entre serenidade e medo é comparada à luta entre duas parcelas antagônicas da personalidade, ou em Le docteur Heráclius Gloss, no qual o personagem homônimo se confronta com um rival, Dagobert Félorme, que possui qualidades similares no que diz respeito ao conhecimento da doutrina da metempsicose.

A presença do duplo nos textos de Maupassant, e também nos de outros autores, não se limita à ação de personagens rivais ou à 
personificação de sentimentos angustiantes. Como propõe Thierry Ozwald, a própria estrutura das narrativas curtas de base realista do século XIX muitas vezes aponta para o duplo, a partir da repetição de determinadas cenas e eventos. Essa repetição, todavia, não é da ordem do idêntico: ela dá espaço a certas modificações que, no decorrer do fluxo narrativo, levam frequentemente a um desfecho negativo por parte do personagem.

Em muitas das narrativas de Maupassant em que o duplo aparece ou é sugerido, o protagonista morre ou se torna louco (Le Horla, Le docteur Héraclius Gloss); em outras, ele não chega a ter um final trágico, mas carrega traumas ou dissabores (Sur l'eau, Lui?, La morte). Nesse aspecto, a história Conte de Noël constitui uma singularidade, por apresentar uma trama na qual o duplo, que poderia ser aqui relacionado ao demônio que possui a protagonista da trama, é vencido. Procurar uma manifestação positiva do duplo, seja em Maupassant ou em algum outro autor realista do século $\mathrm{XIX}$, representaria uma pesquisa muito interessante, mas fadada a uma obtenção mínima de dados.

No mais, o estudo da literatura fantástica permite atraentes articulações com disciplinas como a psicanálise e a antropologia, entre outras. O fantástico, como lugar de incertezas existenciais e de fronteiras evanescentes, está sempre a ser rediscutido: tal como o duplo, a repetição de certas questões, em tese, familiares, sempre conduz a caminhos novos - angustiantes talvez, mas também instigantes. 


\section{REFERÊNCIAS}

BESSIÈRE, Irène (1974). Le récit fantastique: la poétique de I'incertain. Paris: Larousse.

FABRE, Jean (1992). Le miroir de sorcière: essai sur la littérature fantastique. Paris: José Corti.

FREUD, Sigmund (2016). "O inquietante". Paulo César Lima de Souza (Trad.). In . Sigmund Freud: obras completas. Vol.14. São Paulo: Companhia das Letras, p.328-376.

MAUPASSANT, Guy de (1957). Contes et nouvelles. Paris: Albin Michel. 2 vols. TODOROV, Tzvetan (1970). Introduction à la littérature fantastique. Paris: Seuil. 